\title{
Pull-out strength of axially loaded steel rods bonded in glulam parallel to the grain
}

\author{
R. Steiger $\cdot$ E. Gehri $\cdot$ R. Widmann
}

Received: 8 June 2005 / Accepted: 15 November 2005 / Published online: 19 October 2006

(C) RILEM 2006

\begin{abstract}
Bonded-in steel rods are very efficient in withstanding high forces applied to timber members. Investigations of bonded-in rods started in the late eighties of the last century and several design models were published since. By comparing these approaches on base of an extensive literature review a certain degree of discrepancy and partly even contradiction can be found. The paper describes a test program which aimed to study the influence of timber density and of geometric parameters on the pull-out strength of single axially loaded steel rods. Following the GSA ${ }^{\circledR}$ procedure, which is a well established glued-in rods joint in Switzerland, rods with metric thread were bonded in glulam made of Norway spruce lamellas using an epoxy-type adhesive. The tests showed that the influence of the timber density can be quantified by a power function of $\rho$ with an exponent of 0.6. The parameters length of the glued zone $\ell$ and diameter of the hole $d_{H}$ can be summarized in the slenderness ratio $\lambda=\ell / d_{H}$, which itself is related to the mean shear strength in the anchoring zone by an exponent of approximately $-1 / 3$. In order to prevent the specimens from premature splitting, distances between the axis of
\end{abstract}

R. Steiger $(\square) \cdot$ R. Widmann

Empa, Swiss Federal Laboratories for Materials Testing and Research, Wood Laboratory, Überlandstrasse 129, CH-8600 Dübendorf, Switzerland

e-mail: rene.steiger@empa.ch

E. Gehri

Prof. em. ETH, CH-8803 Rüschlikon, Switzerland the rod and the edge of the specimen of 2.3 times the diameter of the rod have been used.

Résumé En utilisant des tiges nervurées collées il est possible d'appliquer des grands charges à des éléments constructifs en bois. Comme résultat de l'exploration des barres métalliques encollées, qui était commencée à la fin des années quatre-vingts du dernier siècle, plusieurs propos de calcul ont été publié. En comparant ces propos de calcul trouvés en cours d'une recherche étendue de la littérature, une certaine divergence et de temps en temps même contradiction peuvent être constatées. L'article-ci décrit une série d'essais en cours de laquelle on voulait examiner l'influence de la densité du bois et de différents paramètres géométriques sur la résistance à la traction axiale d'une seule tige. Les tiges avec filetage métrique ont été collées dans du bois lamellé-collé d'épicéa avec une résine époxy selon la procédure GSA ${ }^{\circledR}$ qui représente un système bien établi en Suisse. Les essais ont montré que l'influence de la densité du bois peut être quantifiée par une fonction potentielle avec un exposant de 0.6. La longueur de la zone collée $\ell$ et le diamètre $d u$ trou $d_{H}$, réunis comme élancement relative $\lambda=\ell / d_{H}$, sont en rapport avec la résistance au cisaillement moyenne de la longueur d'encollage avec un exposant de -1/3. Afin d'éviter un fendillement prématuré dans le bois des distances de 2.3 fois le diamètre de la tige entre son axe et le bord du spécimen ont été réalisées. 
Keywords Glued-in steel rod · Glulam · Pull-out strength · Parallel to the grain · Parameter study . Epoxy

\section{Introduction}

Steel rods bonded in glulam elements are very efficient joints that can withstand high axial forces applied to timber structural members. Research on bonded-in rods started in the late eighties of the last century. Attempts to develop design methods that would optimize the application of such joints were intensified within the last 10 years [1-5].

Several design approaches and code models have been published [6-10]. By comparing these models and approaches on base of an extended literature review, some discrepancy and partly even contradictions between the models, especially regarding the treatment of isolated parameters, were found. On this background, a test program was initiated to study the influence of a selection of these parameters, known or supposed to be determinant on the pull-out strength of single, axially loaded steel rods. Test specimens consisted of rods with a metric screw-thread, bonded with an epoxy-type adhesive into glulam made of Norway spruce (Fig. 1). The tests were focused to determine the influence of timber density $\rho$, length $\ell$ and diameter $d$ of the rod (or the corresponding drill-hole $d_{h}$ respectively) and of the distances between the axis of the rod and the edge of the specimen on the pull-out strength of the rod.

Important objectives of the test program were that it should be based on practically applicable situations and dimensions and that it should enable a comparison with similar test series. These objectives could only be reached by permitting certain compromises regarding

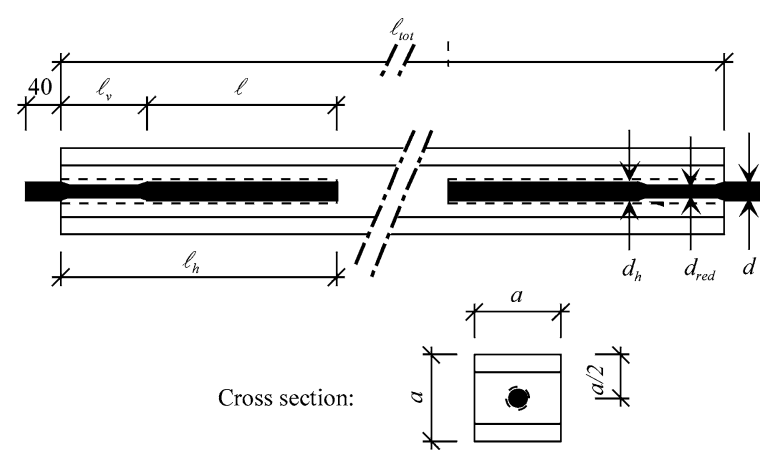

Fig. 1 Geometry of specimens (dimensions see Tables 1 and 2) the test layout. Although for example in practice the use of one single rod will not or hardly ever be the normal case, all tests described here were carried out on connections with one single rod, because the examination of such a connection provides a good basis to study the influence of the parameters mentioned before. In practice the tested GSA ${ }^{\circledR}$-system [11] is optimized in such way that yielding of the steel rod is decisive, thus resulting in a ductile behaviour of the joint. Contrary to practice the aim of the study was to analyse the influence of timber-related parameters on the pull-out strength of the rods. Therefore rods of high yield limit and strength were chosen, in order to provoke shear failure in the timber.

Although the test results and the conclusions are specifically valid for the tested system and loading configuration, it is possible to draw some general conclusions about the quantification of the influence of the parameters focused by the study and to propose an adequate strength model.

\section{Review of existing approaches}

\subsection{Influence of timber density}

Since most of the mechanical properties of timber (of the same species) are known to be more or less directly related to the density of the timber, it is to be supposed that the pull-out strength of glued-in steel rods also depends on the timber density, provided steel yielding and cohesive or adhesive failure are avoided. For screws and screw nails set in timber perpendicular to its grain, the influence of the density on the pull-out strength was demonstrated for example by [12-15] and was taken into account by a power function of the density $\left(\rho^{c}\right)$ with exponents $c$ up to 2.5 [12].

Compared to screws and screw nails, glued-in rods introduce the shear forces into the timber in a different way. While the "anchored" screws rely on direct contact between the timber and the flanks of the thread and therefore on a kind of compression of complex geometry, the glued-in rods transfer the force only at the interface between the rod and the adhesive. The load transfer between the adhesive and the timber is governed mainly by shear and not by compression due to indentation. Being aware of this, a dependence of the pull-out strength of glued-in rods on the timber density can be expected. However this influence should be less 
significant compared to screws and screw nails because the shear strength of timber is affected by the density to a lesser degree than its compression strength.

Researchers have stated different opinions on the influence of the timber density on the pull-out strength of glued-in rods. While some of them (for example: $[16,17])$ derived such an influence from their test results, others asserted the pull-out strength to be independent of timber density [18] or to exhibit poor correlation $[8,19,20]$. Design models derived from the tests take into account the influence of density by power functions $\rho^{c}$ with exponents $c$ in the range of 0 to 1.5 according to the rod-to-grain angle [6, 8-10, 20-24]. All of these design models consider the dependence on the density, if taken into account at all, to be marked more for rods set in parallel to the grain, than for those set perpendicular to the grain.

\subsection{Influence of length and diameter of the} anchoring zone

The diameter and the length of the rod or of the hole respectively (which is a better way of analysing data derived from tests with clear failure in the timber) were shown by different studies (for example by $[8,10,16$, $21,23,25,26])$ to be the dominant influence on the pullout strength of glued-in rods. The glued length $\ell+\ell_{v}$ ( $\ell$ corresponds to the anchoring length, where the load is actually transmitted from the rod to the timber; the length $\ell_{v}$ is a tapered portion of the rod without any load transfer capacity (Fig. 1)). The anchoring length $\ell$ and the diameter $d_{h}$ of the drill-hole can be combined in a single parameter called slenderness ratio $\lambda=\ell / d_{h}$. In [8] a very strong effect of absolute size of the rod and also of the rod's slenderness is presented for brittle adhesives.

\subsection{Influence of the rod's distances to the edge of} the specimen

In order to prevent the timber from early splitting due to tensile stresses perpendicular to the grain, which is part of the multiaxial stresses within the anchoring zone, minimal distances between the rod and the edge of the specimen have to be provided. Early studies on glued-in rods were performed with edge distances of $4 \cdot d[16,25]$. Although sometimes this value was used again later on [8], most of the latest design approaches and experimental studies use distances of $2.5 \cdot d$ between the axis of the rod and specimen's edge [9, 27, 28].

With regard to an optimal performance of the joint in terms of resulting tensile stress in the timber net cross-section the edge distances should be as small as possible. The GSA ${ }^{\circledR}$-system tested in the course of this study, uses edge distance ratios of $2.3 \cdot d$ to $2.4 \cdot d$. In [29] it was reported, that edge distance ratios of $1.5 \cdot d$ resulted in premature splitting of the timber, whilst this was not the case for edge distance ratios $\geq 2 \cdot d$.

\section{Tests}

\subsection{Material properties}

\subsubsection{Timber}

The specimens were cut from glued-laminated timber made of Norway spruce lamellas of $40 \mathrm{~mm}$ thickness. The lamellas were free from any finger-joints or significant anatomical defects such as big knots and deviations of grain angle, in order to avoid negative influence on the results by these parameters. The glulam members were assembled using a melamine urea formaldehyde (MUF) adhesive. Two pairs of glulam beams were produced from lamellas with clearly distinct distributions of density (Fig. 2 and Table 3), in order to quantify the influence of the timber density on the pull-out strength of the rods. Every single specimen was cut from a beam with a desired density respectively.

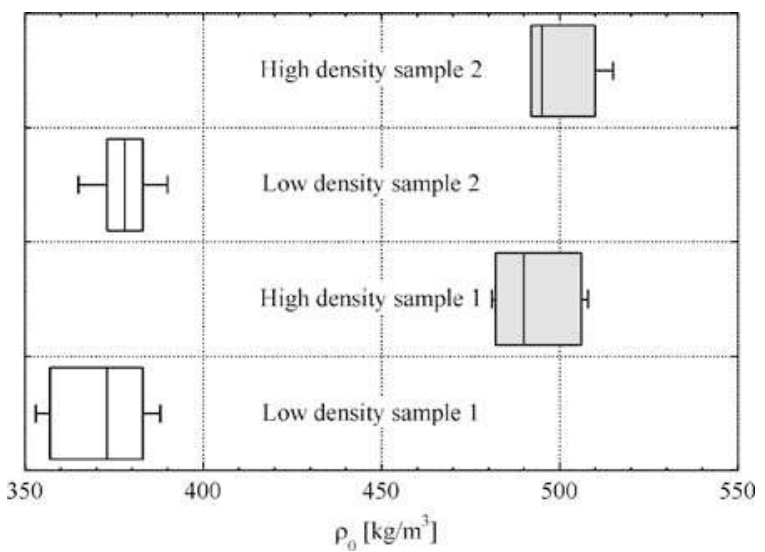

Fig. 2 Box-plots of lamellae's densities $\rho_{0}$ used for the four glulam beams which served as base for the production of the specimens 


\subsubsection{Adhesive}

The rods were set using a system called GSA ${ }^{\circledR}$ by n'H (Neue Holzbau AG, Switzerland) [11]. For the $\mathrm{GSA}^{\circledR}$-system a special epoxy-type adhesive, free from any solvent and curing at ambient temperature has been developed by ASTORit AG, Switzerland. This adhesive performs well, as company internal tests showed. Shear strengths up to $35 \mathrm{~N} / \mathrm{mm}^{2}$ were reached between two threaded steel surfaces bonded together. Tests on threaded steel rods bonded in ash established shear failure in timber at nominal shear strength levels of 16 to $18 \mathrm{~N} / \mathrm{mm}^{2}$.

\subsubsection{Steel rods}

In practice, joints with glued-in rods should be designed in such way that steel failure (yielding) occurs (Fig. 3) and not wood- or adhesive failure in order to achieve a ductile rather than a brittle rupture. The GSA ${ }^{\circledR}$-system considers this fact by reducing the cross-section of the steel rods within a certain length $\ell_{v}$, based on an investigation by Fabris [30]. Removing the rod's thread within the length $\ell_{v}$ also leads to a shift of the anchoring zone to the interior of the specimens. Stress concentrations are reduced and splitting due to shear forces and stresses perpendicular to the grain are less likely to happen $[26,30,31]$. The drill-hole was filled with glue on its whole length $\ell+\ell_{v}$. However, it was assumed that the zone along the length $\ell_{v}$ can not contribute to the pull-out resistance due to the lack of mechanical indentation of rod and adhesive. The length $\ell_{v}$ was taken to be $5 \cdot d$.

The steel rods with metric threads M12, M16 and M20 were zinc coated and corresponded to quality 8.8

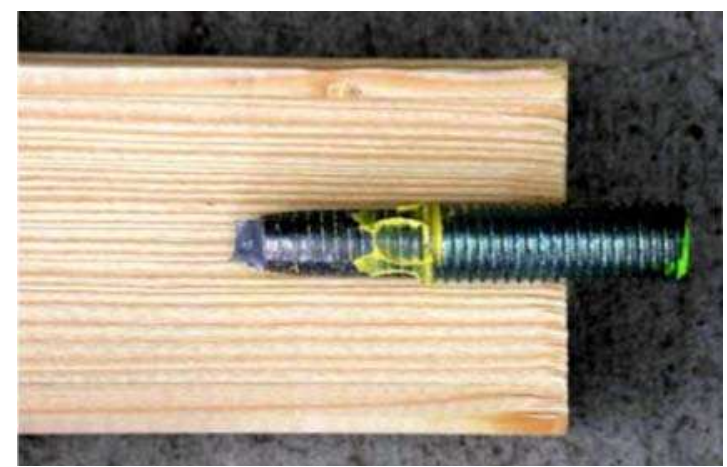

Fig. 3 Steel failure (yielding of the rod)

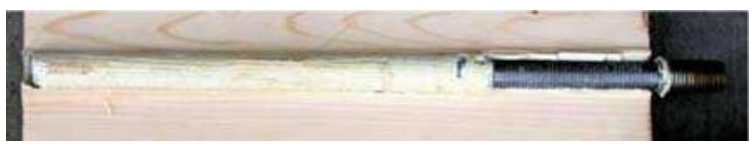

Fig. 4 Shear failure in timber

(nominal yielding point: $f_{y} \approx 640 \mathrm{~N} / \mathrm{mm}^{2} / \varepsilon_{y} \approx 3 \%$ and nominal ultimate tensile strength: $f_{u} \approx 800 \mathrm{~N} / \mathrm{mm}^{2}$ ). This high-quality steel was chosen in order to provoke timber shear failure (Fig. 4) rather than steel failure (Fig. 3). The rods were set in holes with diameters $d_{h}$ that exceeded the rod diameter by $2 \mathrm{~mm}$.

\subsection{Specimens, equipment and procedure}

\subsubsection{Specimens}

The rods set parallel to the grain were tested in a double-ended (pull-pull) configuration (Fig. 5). In order to give the joints an optimal performance both the timber and the steel elements should have a similar stiffness $\left(A_{\text {Timber }} \cdot E_{\text {Timber }} \approx A_{\text {Steel }} \cdot E_{\text {Steel }}\right), A$ being the cross-section and $E$ the modulus of elasticity [26, $30]$. The ratio $A_{\text {Timber }} / A_{\text {Steel }}$ should therefore be equal to

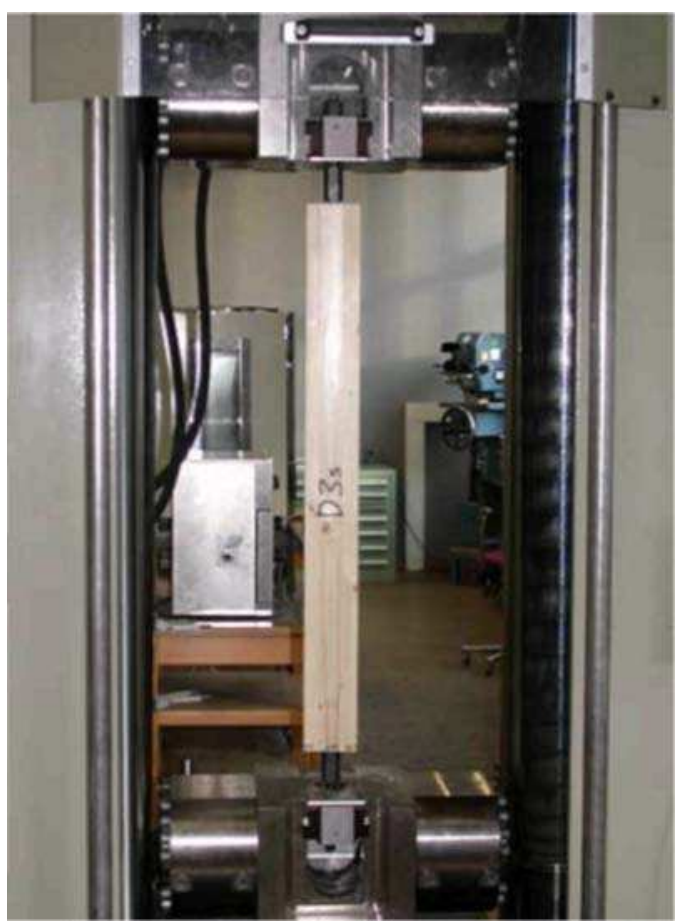

Fig. 5 Tensile test of specimens in pull-pull configuration 
Table 1 Geometric properties of specimens in reference to Fig. 1
Table 2 Geometric properties of specimens for evaluation of cross-section in reference to Fig. 1

\begin{tabular}{|c|c|c|c|c|c|c|}
\hline Series & $d-d_{h}[\mathrm{~mm}]$ & $a[\mathrm{~mm}]$ & $\ell_{v}[\mathrm{~mm}]$ & $\ell[\mathrm{mm}]$ & $\lambda=\ell / d_{h}$ & $\ell_{\text {tot }}[\mathrm{mm}]$ \\
\hline \multirow[t]{4}{*}{ M12 } & \multirow[t]{4}{*}{$12-14$} & \multirow[t]{4}{*}{55} & \multirow[t]{4}{*}{60} & 105 & 7.5 & 580 \\
\hline & & & & 140 & 10 & 650 \\
\hline & & & & 175 & 12.5 & 720 \\
\hline & & & & 210 & 15 & 780 \\
\hline \multirow[t]{4}{*}{ M16 } & \multirow[t]{4}{*}{$16-18$} & \multirow[t]{4}{*}{75} & \multirow[t]{4}{*}{80} & 140 & 7.78 & 700 \\
\hline & & & & 175 & 9.72 & 780 \\
\hline & & & & 220 & 12.2 & 880 \\
\hline & & & & 270 & 15 & 970 \\
\hline \multirow[t]{4}{*}{ M20 } & \multirow[t]{4}{*}{$20-22$} & \multirow[t]{4}{*}{95} & \multirow[t]{4}{*}{100} & 175 & 7.96 & 980 \\
\hline & & & & 220 & 10.0 & 1070 \\
\hline & & & & 275 & 12.5 & 1180 \\
\hline & & & & 330 & 15 & 1240 \\
\hline
\end{tabular}

\begin{tabular}{lllllll}
\hline Series & $d-d_{h}(\mathrm{~mm})$ & $\ell(\mathrm{mm})$ & $\ell_{v}(\mathrm{~mm})$ & $\ell_{\mathrm{tot}}(\mathrm{mm})$ & $a(\mathrm{~mm})$ & $e=0.5 \cdot a / d$ \\
\hline M16 & $16-18$ & 175 & 80 & 780 & 56 & 1.75 \\
& & & & 65 & 2.03 \\
& & & & 75 & 2.34 \\
& & & 85 & 2.66 \\
& & & 100 & 3.13 \\
& & & 120 & 3.75 \\
\hline
\end{tabular}

the ratio $E_{\text {Steel }} / E_{\text {Timber }}$ which is approximately 16 to 20 for Norway spruce. From the practical point of view, high ratios of $A_{\text {Timber }} / A_{\text {Steel }}$ are unattractive because of a poor performance of the joint itself, regarding the resulting tensile stress in the glulam element. However, in order to prevent early splitting of timber due to stress concentrations, the cross-sections of the specimens had to be designed in such way that edge distance ratios from $2.3 \cdot d$ to $2.4 \cdot d$ resulted and this represented ratios of $A_{\text {Timber }} / A_{\text {Steel }}$ from 37 to 39 . Geometry and dimensions of the specimens are shown in Table 1 and in Fig. 1. In general there were four specimens per each combination of rod diameter, timber density and anchoring length resulting in a total number of 96 specimens with 192 glued-in rods.

In order to study the influence of the distance between the rod and the edge of the specimen, a supplementary series of 24 specimens (48 rods) with edge distance ratios between $1.75 \cdot d$ and $3.75 \cdot d$ was additionally tested (Table 2).

\subsubsection{Equipment and procedure}

All tests were carried out on a universal tension testing machine (Fig. 5) with a maximal error of the force
Table 3 Sample statistics of lamellae's densities

\begin{tabular}{lllll}
\hline & \multicolumn{4}{c}{ Density $\rho_{0}\left(\mathrm{~kg} / \mathrm{m}^{3}\right)$} \\
\cline { 2 - 5 } Parameter & Low 1 & High 1 & Low 2 & High 2 \\
\hline Sample size $n$ & 12 & 12 & 12 & 12 \\
Mean value & 371 & 493 & 378 & 498 \\
Maximum & 388 & 508 & 390 & 515 \\
Minimum & 353 & 481 & 365 & 492 \\
Standard deviation & 13.2 & 10.8 & 8.38 & 7.67 \\
Coeff. of variation & $3.6 \%$ & $2.2 \%$ & $2.2 \%$ & $1.5 \%$ \\
$\rho_{k}{ }^{\text {a }}$ & 349 & 475 & 364 & 485 \\
\hline
\end{tabular}

${ }^{\mathrm{a}} 5$ th percentile assuming normal distribution and $n=\infty$

measurement $<1 \%$. The rate of loading was taken in accordance with EN 26891 [32].

\section{Results and discussion}

\subsection{General}

An overview of the test results is given in Fig. 6. Even though it was only verified by spot checks, there was strong evidence that the pull-out of the rods occurred due to shear failure of the wood around the anchoring zone of the rods (Fig. 4). Visible splitting and cracking 


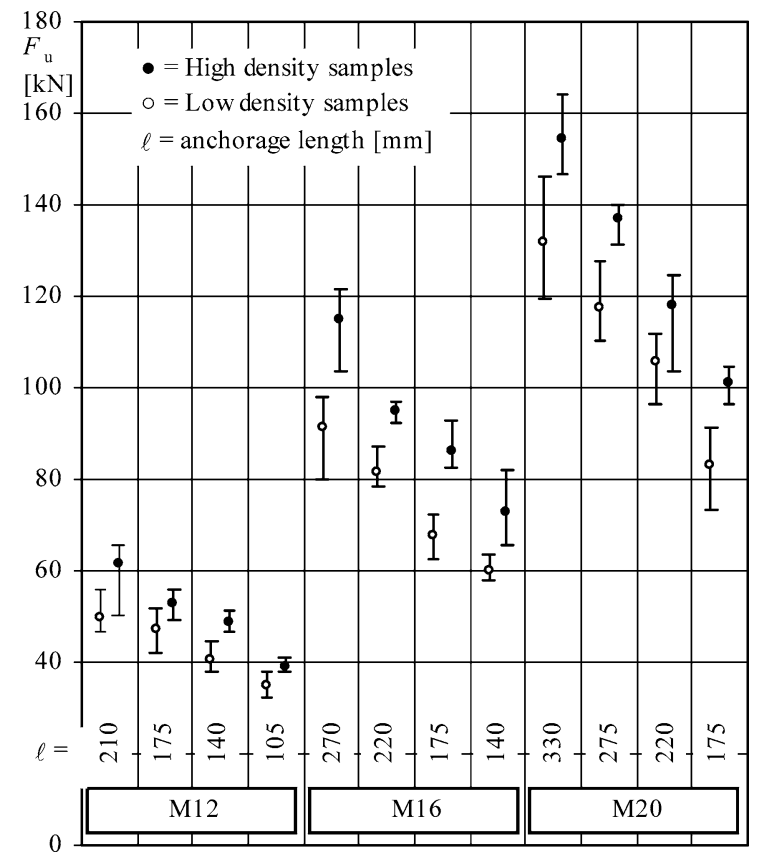

Fig. 6 Overview of ultimate loads $F_{u}$. (Maximum, Mean, Minimum). Number of specimens $n=4$ for all series except for $<M 16-270 L \& H>$ and $<M 20-330 L>$ with $n=3$. Values for series $<M 12-210>$ include steel failures or wood-tension failures

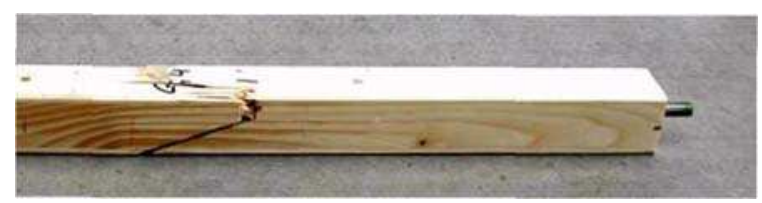

Fig. 7 Tensile failure in timber

at the ends of the specimens occurred at about $65 \%$ of all tests. However, there were no significant differences between the failure loads of specimens with and without external signs of cracking/splitting. Cracking therefore did not influence the pull-out strengths and was regarded as being a consequence of the internal shear failure of the wood. The rupture of three out of the four specimens $<$ M12-210 High density $>$ occurred due to steel failure and within the series $<M 12-210$ Low density $>$ two out of the four specimens showed tension failure in timber on a very low strength level (Fig. 7). Since the failure mode of these specimens was different to that aimed at in the strength model, both series were excluded from further analysis. (Timber tensile failure in practice has to be avoided by adequate quality control of the glulam members used for structural purposes.)
The recorded ultimate loads of series M20 (low density) and M16 (both low and high density) with the longest anchoring lengths had significantly higher coefficients of variation compared to all other series. In all three series mentioned this was due to one single low value. Investigations on this showed significantly tilted positions of the respective rods which caused eccentric loading. It was decided to take no account of these single values at the following analysis.

In general Fig. 6 gives a good impression on the influence of timber density, rod diameter and rod length on the pull-out-strength of the rods. The influence of these individual parameters is looked at in greater detail in the following.

\subsection{Influence of timber density}

Within every series with identical geometrical properties, the mean value of the pull-out strengths $F_{u \text {,mean }}$ of the specimens with a high wood density was significantly higher than that of the specimens with a low wood density. The mean ratio of high density wood (H) to low density wood (L) was found to be $\rho_{H} / \rho_{L}=$ 1.33. The ratio of the respective mean ultimate loads $F_{u, H} / F_{u, L}$ varied from 1.11 to 1.28 with a mean value of 1.18. As only high and low density samples were tested, no statement to the progression of density ratio $\rho_{H} / \rho_{L}$ against load ratio $F_{u, H} / F_{u, L}$ could be made on base of the test results. In literature often a power function is given to describe their dependency. On this base a mean value of the exponent $c_{\text {mean }}=0.60$ for $\left(F_{u, H} / F_{u, L}\right)=$ $\left(\rho_{H} / \rho_{L}\right)^{c}$ could be calculated. This value matches results of other studies very well, indicating $c=0.55$ for epoxy-type adhesives [33] and at the same time rejects proposals of higher $c$-values.

\subsection{Influence of anchoring length and of drill-hole diameter}

As already mentioned initially, the tests were planned to follow a certain range of geometrical proportions in terms of drill-hole diameter $d_{h}$ and anchoring length $\ell$, or in combination also represented by the slenderness ratio $\lambda=\ell / d_{h}$. Besides analysing the test results with regard to $\lambda$, the influences of the individual parameters $\ell$ and $d_{h}$ were studied, in order to get an idea about their significance. The nominal shear strength $f_{v, 0 \text {,mean }}$ was calculated assuming a constant distribution of the shear stresses over the anchoring length $\ell$. However, 


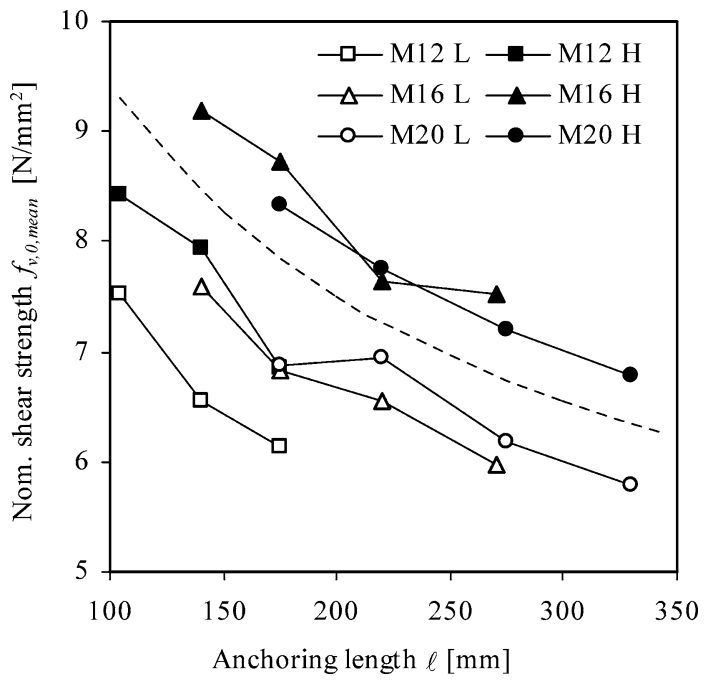

Fig. 8 Nominal shear strength versus anchoring length. The dotted line represents the kind of progression if a dependence $f_{v, 0 \text {, mean }}$ against $\left(\ell_{2} / \ell_{1}\right)^{-1 / 3}$ is assumed $\left(\ell_{2}>\ell_{1}\right)$

it is known from respective finite element simulations that in case of rods glued-in parallel to the grain, the stress distribution is uneven with peaks at both ends of the anchoring zone [20, 34, 35].

With increasing anchoring lengths the ultimate loads also increased (Fig. 6) but the nominal shear strengths decreased (Fig. 8). A reason for the decreasing shear strengths is seen in the mentioned distribution of the shear stresses along the rods length. For the description of the dependency of shear strengths against anchoring length an approach based on $\ell^{-1 / 3}$ is suggested.

Regarding the influence of the slenderness ratio $\lambda=$ $\ell / d_{h}$ on the nominal shear strength $f_{v, 0 \text {,mean }}$, a power function $\lambda^{-1 / 3}$ fits the test results well (Fig. 9).

The analysis of the influence of the drill-hole diameter on nominal shear strength was based on the comparison of series with similar anchoring lengths but different hole- and rod diameters. In Fig. 6 it clearly appears that ultimate loads increased with increasing diameters. However, the influence of the drill-hole diameter on the nominal shear strength could not be clearly verified (Fig. 10). For most of the series nominal shear strength increased with increasing diameter $d_{h}$ but for a glued length of $\ell=220 \mathrm{~mm}$ it decreased with an increasing diameter from M16 to M20.

Based on an approach $\lambda^{-1 / 3}$, the influence of the hole-diameter $d_{h}$ on the pull-out strength of rods set parallel to the grain needs to be $d_{h}{ }^{1 / 3}$ if a constant

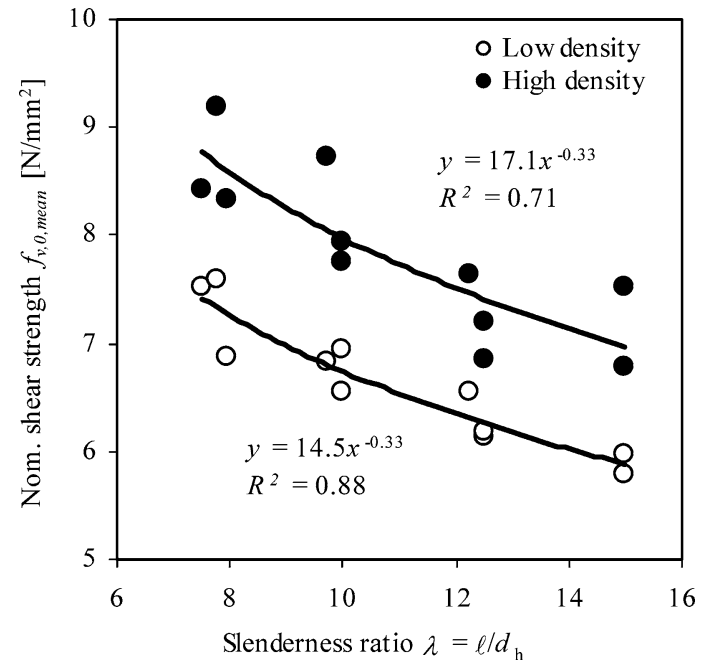

Fig.9 Nominal shear strength versus slenderness ratio $\lambda=\ell / d_{h}$

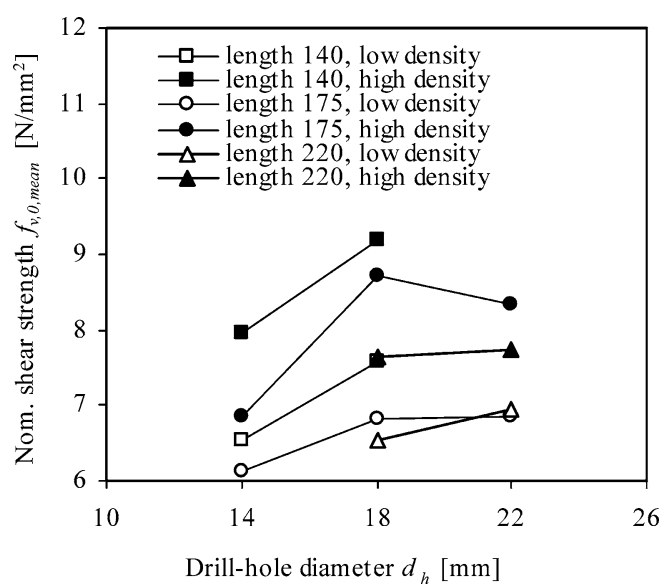

Fig. 10 Mean value of density-adjusted nominal shear strength versus drill-hole diameter $d_{h}$ for three different anchoring lengths

length is assumed. This could not be proved in detail on base of the test results.

In general it can be stated, that if the single parameters anchoring length $\ell$ and diameter of the drill-hole $d_{h}$ are taken as a base for the determination of the pullout strength $f_{v, 0 \text {, mean }}$ of rods set parallel to the grain, both parameters would have to be put in consideration and both with different exponents. An approach based on the slenderness $\lambda$ therefore seems to be the better solution.

\subsection{Influence of timber cross-section}

In Fig. 11 it can clearly be seen, that for edge distance ratios smaller than $2.3 \cdot d$ the pull-out strength values 
Table 4 Resulting tensile stress in wood (Mean value of sample means of ultimate loads $F_{u}$ for all series with $\lambda$ from 7.5 to 12.5 and for both high and low density samples)

\begin{tabular}{lccc}
\hline Rods & M12 & M16 & M20 \\
\hline Mean $F_{u, \text { mean }}(\mathrm{kN})$ & 43.8 & 77.2 & 110 \\
$\sigma_{t, 0}\left(\mathrm{~N} / \mathrm{mm}^{2}\right)$ & 14.5 & 13.7 & 12.2 \\
\hline
\end{tabular}

Table 5 Resulting tensile stress in wood (Max values of ultimate loads $F_{u}$ for high density samples)

\begin{tabular}{llll}
\hline Rods & M12 & M16 & M20 \\
\hline $\operatorname{Max} F_{u}(\mathrm{kN})$ & $65.7^{\mathrm{a}}$ & 121 & 164 \\
$\sigma_{t, 0}\left(\mathrm{~N} / \mathrm{mm}^{2}\right)$ & $21.7^{\mathrm{a}}$ & 21.5 & 18.2
\end{tabular}

${ }^{\text {a }}$ Steel failure (yielding of the rod)

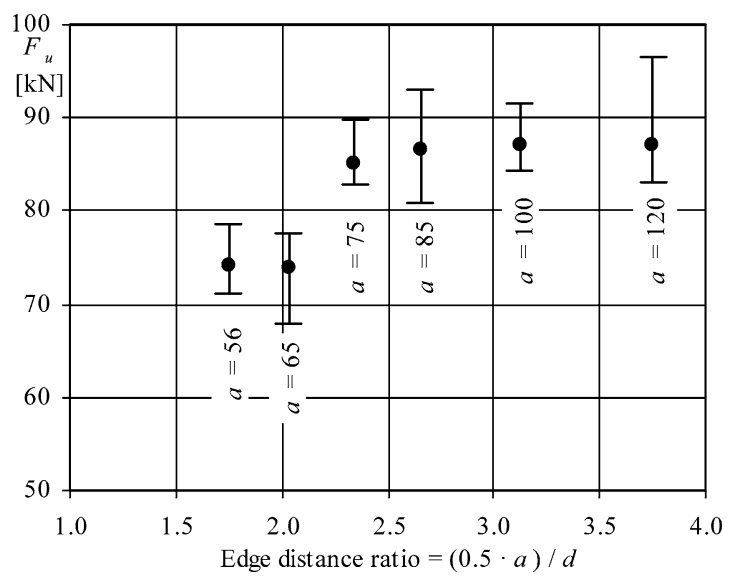

Fig. 11 Influence of the rod's distance to the edge of the specimen

decreased significantly, which is in accordance with requests of most actual design approaches. Edge distance ratios smaller than $2.3 \cdot d$ therefore should be avoided in order to prevent premature splitting of the timber resulting in low pull-out strength values.

With regard to an optimal load transfer capacity of the joint the timber cross-section should be as small as possible. A comparison of the resulting tensile stresses in the timber members shows, that for a given edge distance ratio of 2.3. $d$ the load transfer capacity from steel to timber was better for the smaller diameters (Table 4). With regard to an optimal load transfer capacity preference therefore should be given to rods with smaller diameter. For high density glulam and slenderness ratio $\lambda=15$ maximum tensile stresses over $20 \mathrm{~N} / \mathrm{mm}^{2}$

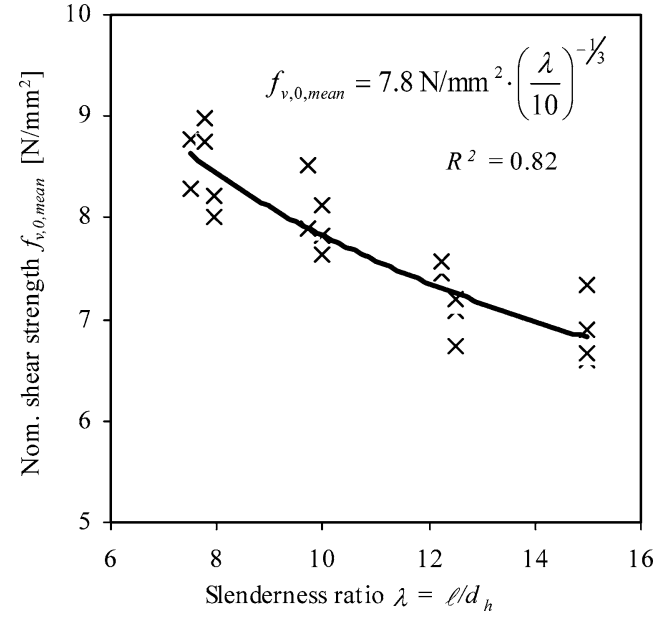

Fig. 12 Design model in comparison to density-adjusted ( $\rho=$ $480 \mathrm{~kg} / \mathrm{m}^{3}$ ) mean values of test results

were reached with respect to the timber cross-section (Table 5).

\subsection{Pull-out strength model}

The test results permit to propose a strength model for the calculation of the pull-out strength on a mean level. For wood density a reference value of $\rho_{\text {mean }}=$ $480 \mathrm{~kg} / \mathrm{m}^{3}$ being near to the mean density of the high density samples serves as base. On the geometrical side $\lambda=10$ which represents a value in the middle range of the tested geometries was chosen as reference base. With the mean values of the test results adjusted to the mentioned $\lambda$ and $\rho$, a corresponding shear strength of $7.8 \mathrm{~N} / \mathrm{mm}^{2}$ results. Thus, the nominal shear strength of single, axially loaded rods set parallel to grain results in:

$f_{v, 0, \text { mean }}=7.8 \mathrm{~N} / \mathrm{mm}^{2} \cdot\left(\frac{\lambda}{10}\right)^{-1 / 3} \cdot\left(\frac{\rho}{480}\right)^{0.6}$

The pull-out strength thus can be calculated with $F_{a x \text {,mean }}=f_{v, 0, \text { mean }} \cdot \pi \cdot d_{h} \cdot \ell$

$f_{v, 0, \text { mean }}\left[\mathrm{N} / \mathrm{mm}^{2}\right], \rho\left[\mathrm{kg} / \mathrm{m}^{3}\right], \lambda=\ell / d_{h}[-], \ell[\mathrm{mm}], d_{h}$ $[\mathrm{mm}], F_{a x, \text { mean }}[\mathrm{N}]$.

Figure 12 shows the fit of this equation with the density adjusted test results.

The use of the strength equation is restricted to:

- single rods glued-in parallel to the grain and loaded axially in tension 
- slenderness ratios $\lambda=\ell / d_{h}$ in the range of $7.5 \leq \lambda \leq 15$

- rod diameters $d$ of 12 to $20 \mathrm{~mm}$

- length $\ell_{v}=5 \cdot d$

- edge distances $\geq 2.3 \cdot d$

- glulam made of Norway spruce or other coniferous timber with similar properties and characteristic values of density in the range of 350 to $500 \mathrm{~kg} / \mathrm{m}^{3}$.

The proposed strength model only covers the expected mean pull-out loads due to shear failure in the wood around the glued zone. In addition a control of the stresses in the steel bar and in the timber member (net cross-section) is necessary. In practice however the above pull-out strength formula only allows to calculate the maximum capacity of the joint for given geometrical parameters and for a certain timber density. Actually the joint should rather be designed in such a way that (ductile) steel failure occurs and (brittle) timber failure is prevented. Failure of the bond line or internal adhesive failure is to be prevented in any case in order to get ductile steel failure and optimal performance of the glued-in rod joint.

\section{Conclusions}

Based on the test results it can be stated, that for the used GSA ${ }^{\circledR}$-system:

- the pull-out strength of rods bonded parallel to the grain in glulam made of Norway spruce depends on the density of the timber around the anchoring zone. The influence of the density is clearly marked and can be covered by a power function $\rho^{c}$ with an exponent of $c=0.6$.

- the influence of the anchoring length $\ell$ on ultimate load values is marked and can be taken into account by an adjustment to the formulas based on $\ell^{-1 / 3}$.

- an influence of the diameter $d_{h}$ of the drill-hole on the pull-out strength could not be clearly evaluated.

- a dependence of ultimate loads on the slenderness ratio $\lambda=\ell / d_{h}$, which can be quantified by $\lambda^{-1 / 3}$ could be shown.

- with regard to optimal load transfer capacity from steel to timber, rods with smaller diameter should be given preference.

Acknowledgements The presented work was funded partly by the Swiss State Secretariat for Education and Research SER within the framework of COST Action E34 'Bonding of Timber'. The assistance of T. Strahm (sample logistics) and K. Weiss (mechanical testing) is gratefully acknowledged.

\section{References}

1. (2001) Proceedings of the International RILEM-Symposium on Joints in Timber Structures, Stuttgart, Germany

2. (1995) Proceedings of the CIB-W18 Meeting Twenty-Eight, Copenhagen, Denmark

3. (1999) Proceedings of the CIB-W18 Meeting Thirty-Two, Graz, Austria

4. (2000) Proceedings of the CIB-W18 Meeting Thirty-Three, Delft, The Netherlands

5. (2001) Proceedings of the CIB-W18 Meeting Thirty-Four, Venice, Italy

6. Riberholt H (1988) Glued bolts in glulam - proposal for CIB code. Proceedings of the CIB-W18 Meeting Twenty-One, Parksville, Vancouver Island, Canada, Paper 21-7-2

7. Möhler K, Siebert W (1981) Glued-in rods, Holzbau-StatikAktuell 6:4-6 (only available in German)

8. Aicher S, Gustafsson PJ, Wolf M (1999) Load displacement and bond strength of glued-in rods in timber influenced by adhesive, wood density, rod slenderness and diameter. Proceedings of the International RILEM Symposium on Timber Engineering, Stockolm, Sweden, 10

9. ENV 1995-2 1997. Eurocode 5 - Design of timber structures (CEN, Bruxelles, 1997).

10. Gustafsson P-J, Serrano E, Aicher S, Johansson C-J (2001) A strength design equation for glued-in rods. Proceedings of the International RILEM Symposium on Joints in Timber Structures, Stuttgart, Germany, 323-332

11. Strahm T (2000) The GSA-system of anchorage: efficient and easy to design. Proceedings of the $32 \mathrm{SAH}-$ Fortbildungskurs "Verbindungstechnik im Holzbau, Weinfelden, Switzerland, 165-169 (only available in German)

12. Ehlbeck J (1976) Tests on special nails for timber structures, Holz als Roh- und Werkstoff 34(7):205-211 (only available in German)

13. Meierhofer U (1988) Screw withdrawal resistance and strength of spruce and fir. Holz als Roh- und Werkstoff 46(1):15-17 (only available in German)

14. Görlacher R (1990) Examination of old structural timber: measurement of withdrawal resistance. bauen mit holz 92(12):904-908 (only available in German)

15. Werner H, Siebert W (1991) New investigations of nails in timber structures. Holz als Roh- und Werkstoff 49(5):191198 (only available in German)

16. Gerold M (1992) Compound of timber and threaded steel bars. Bautechnik 69(4):167-178 (only available in German)

17. Serrano E (2001) Glued-in rods for timber structures - an experimental study of softening behaviour. Materials and Structures 34:228-234

18. Kemmsies M (1999) Comparison of pull-out strengths of 12 adhesives for glued-in rods for timber structures. SP Report 20 (SP Swedish National Testing and Research Institute, 1999) 
19. Bengtsson C, Johansson C-J (2000) Test methods for gluedin rods for timber structures. Proceedings of the CIBW18 Meeting Thirty-Three, Delft, The Netherlands, Paper 33-7-8

20. Bernasconi A (2001) Behaviour of axially loaded glued-in rods - requirements and resistance, especially for spruce timber perpendicular to the grain direction. Proceedings of the CIB-W18 Meeting Thirty-Four, Venice, Italy, Paper 34-7-6

21. Gerold M (1993) Application of threaded glued-in steel bolts with an applied load in direction of the pin. Bautechnik 70(10):603-613 (only available in German)

22. Gehri E (1996) Load transfer by means of steel bars. Proceedings of the 28 SAH-Fortbildungskurs "Brettschichtholz", Weinfelden, Switzerland, 111-143 (only available in German)

23. Kangas J (2000) Capacity, fire resistance and gluing pattern of the rods in V-connections. Proceedings of the CIB-W18 Meeting Thirty-Three, Delft, The Netherlands, Paper 33-710

24. Gehri E (1997) Background paper on glued-in rods. Document 108 rev. (CEN, Bruxelles)

25. Möhler K, Hemmer K (1981) Glued-in rods. bauen mit holz 83(5):296-298 (only available in German)

26. Gehri E (2000) Re-investigation of classical joints. Proceedings of the 17 Dreiländer Holztagung Holz: Architecture Research - Technology, Lucerne, Switzerland, 43-50 (only available in German)

27. Blass HJ, Laskewitz B (1999) Effect of spacing and edge distance on the axial strength of glued-in rods. Proceedings of the CIB-W18 Meeting Thirty-Two, Graz, Austria, Paper 32-7-12

28. Bengtsson C, Johansson C-J (2001) Girod - glued-in rods for timber structures. Proceedings of the CIB-W18 Meeting Thirty-Four, Venice, Italy, Paper 34-7-8

29. Riberholt H (1986) Glued bolts in glulam. Proceedings of the CIB-W18 Meeting Nineteen, Florence, Italy, Paper 19-7-2

30. Fabris A (2001) Improved tensile strength parallel to the grain of structural timber by means of a compound with threaded steel bars. phd thesis Nr. 14050, ETH Zurich, Switzerland (only available in German)

31. Gehri E (2001) Ductile behaviour and group effect of gluedin steel rods. Proceedings of the International RILEM Symposium on Joints in Timber Structures, Stuttgart, Germany, 333-342

32. EN 26891 (1991) Timber structures - joints made with mechanical fasteners: general principles for the determination of strength and deformation characteristics (CEN, Bruxelles)

33. Kangas J (1994) Joints of glulam structures based on gluedin ribbed steel rods. VTT Publication 196 (VTT, Helsinki, Finland)

34. Del Senno M, Piazza M, Tomasi R (2004) Axial glued-in steel timber joints - experimental and numerical analysis, Holz als Roh- und Werkstoff 62:137-146

35. Deng JX, Moss PJ, Buchanan AH (1998) Glued bolts in glulam - an analysis of stress distribution. Proceedings of the 5th World Conference on Timber Engineering, Lausanne, Switzerland, 206-213 